If this occurs as long before the onset of preterm labour as does the increase in the saliva oestriol to progesterone ratio before the spontaneous onset of labour at term it might be possible to use measurements of this ratio to predict preterm labour-and so initiate treatment in time to prevent its occurrence in some cases. Studies are currently underway to address this issue.

We are very grateful to the University College Appeal Trust for the support of JD and to Clare Thomson for excellent secretarial work.

\footnotetext{
References

1 Tamby Raja RL, Anderson ABM, Turnbull AC. Endocrine changes in premature labour. BrMed f 1974; ;iv:67-71.

2 Cousins LM, Hobel CJ, Chang RJ, Okada DM, Marshall JR. Serum progesterone and estradiol$17 \beta$ levels in premature and term labor. Am $\mathcal{O}$ Obstet Gynecol 1977;127:612-5.

3 Csapo AL. The "seesaw" theory of parturition. In: Knight J, O'Connor M, eds. The fetus and birth. Amsterdam: Elsevier North Holland, 1977:159-210.

4 Bell R. Antenatal oestradiol and progesterone concentrations in patients subsequently having preterm labour. Br $\mathcal{X}$ Obstet Gynaecol 1983;90:888-91.

5 Block BSB, Liggins GC, Creasy RK, Preterm delivery is not predicted by serial estradiol or progesterone concentration measurements. Am J Obstet Gynecol 1984;150:716-22.

6 McGarrigle HHG, Lachelin GCL. Increasing saliva (free) oestriol to progesterone ratio in late pregnancy: a role for oestriol in initiating spontaneous labour in man? $\mathrm{Br} M$ Med $\mathcal{f} 1984 ; 289: 457-9$.

7 Darne J, McGarrigle HHG, Lachelin GCL. Saliva oestriol, oestradiol, oestrone and progesterone levels in pregnancy: spontaneous labour at term is preceded by a rise in the saliva oestriol progesterone ratio. Br $\mathcal{F}$ Obstet Gynaecol (in press).

8 Wiegerinck MAHM, Poortman J, Donker TH, Thijssen JHH. In vivo uptake and subcellular
}

distribution of tritium-labeled estrogens in human endometrium, myometrium, and vagirm f Clin Endocrinol Metab 1983;56:76-86. 9 Schatz F, Markiewicz L, Gurpide E. Effects of estriol on PGF2 ${ }_{a}$ output by cultures of human endometrium and endometrial cells. J Steroid Biochem 1984;20:999-1003.

10 Anderson ABM, Laurence KM, Davies K, Campbell H, Turnbull AC. Fetal adrenal weight afit the cause of premature delivery in human pregnancy. Fourmal of Obstetrics and Gynaecology of the British Commonwealth 1971;78:481-8.

11 Garfield RE, Hayashi RH. Appearance of gap junctions in the myometrium of women during labor. Am $\mathcal{O}$ Obstet Gynecol 1981;140:254-60.

12 Fuchs A-R, Fuchs F, Husslein P, Soloff MS. Oxytocin receptors in the human uterus durif pregnancy and parturition. Am $\mathcal{f}$ Obstet Gynecol 1984;150:734-41.

13 Sellers SM, Mitchell MD, Bibby JG, Anderson ABM, Turnbull AC. A comparison of plasm prostaglandin levels in term and preterm labour. Br $\mathcal{Y}$ Obstet Gynaecol 1981;88:362-6.

$14 \mathrm{Katz} M$, Newman RB, Gill PJ. Assessment of uterine activity in ambulatory patients at high risk preterm labor and delivery. Am $\mathcal{f}$ Obstet Gynecol 1986;154:44-7.

15 Takahashi $\mathrm{K}$, Diamond $\mathrm{F}$, Bieniarz J, Yen $\mathrm{H}$, Burd $\mathrm{L}$. Uterine contractility and oxyto sensitivity in preterm Naeye RL, Peters EC. Causes and consequences of premature rupture of fetal membranes. Lancer 1980;i:192-4.

17 Regan JA, Chao S, James LS. Premature rupture of membranes, preterm delivery, and group streptococcal colonization of mothers. Am $\mathcal{J}$ Obstet Gynecol 1981;141:184-6.

18 Bejar R, Curbelo V, Davis C, Gluck L. Premature labor. II. Bacterial sources of phospholipase Obstet Gynecol 1981;57:479-82.

19 Lamont RF, Rose M, Elder MG. Effect of bacterial products on prostaglandin E production by amnion cells. Lancet 1985;ii:1331-3.

20 Fedrick J. Antenatal identification of women at high risk of spontaneous pre-term birth. $\mathrm{Br}-7$ Obstet Gynaecol 1976;83:351-4.

21 Creasy RK, Gummer BA, Liggins GC. System for predicting spontaneous preterm birth. Obs Gynecol 1980;55:692-5.

22 Westergaard JG, Teisner B, Hau J, Grudzinskas JG. Placental protein measurements 올 complicated pregnancies. III. Premature labour. Br J Obstet Gynaecol 1984;91:1230-3.

23 Castle BM, Turnbull AC. The presence or absence of fetal breathing movements predicts outcome of preterm labour. Lancet 1983;ii:471-2.

(Accepted 12 November 1986)

\title{
Impact of gestrinone on the course of asymptomatic endometriosis
}

\author{
ERIC J THOMAS, IAN D COOKE
}

\begin{abstract}
A new drug, gestrinone, was subjected to the first double blind, randomised placebo controlled trial of any treatment of endometriosis. The disease deteriorated in eight $(47 \%)$ of the 17 patients prescribed placebo (95\% confidence limits $23 \%$ and $71 \%$ ) compared with none of the 18 patients prescribed gestrinone $(p=0.002)$. There was a difference in elimination of the endometriosis in the gestrinone group compared with placebo but this was not statistically significant $(p=0.057)$. There was a significant difference in improvement of the disease in the gestrinone group compared with placebo $(p=0.004)$, confirming that gestrinone is an effective treatment of endometriosis.

Endometriosis deteriorates in at least $23 \%$ of patients; as it is impossible to predict in whom this will happen, treatment appears to be warranted in all cases.
\end{abstract}

\section{Introduction}

Androgens, ${ }^{1}$ progestogens, ${ }^{2}$ danazol, ${ }^{36}$ and luteinising hormone releasing hormone agonists ${ }^{78}$ have all been shown to improve endometriosis either clinically or visually in uncontrolled trials.

\footnotetext{
University Department of Obstetrics and Gynaecology, The Jessop Hospital for Women, Sheffield

ERIC J THOMAS, MRCOG, lecturer

IAN D COOKE, FRCOG, professor

Correspondence to: Dr Thomas.
}

Before the advent of laparoscopy only symptomatic disease wâ treated, but now it is becoming increasingly common to diagno asymptomatic disease, especially in infertile women. The relevance of the finding is unknown and it may be solely a reflection of a increased prevalence of the disease in nulliparous patients, who ate overrepresented in infertile women. ${ }^{9}$ The problem is compounder by the fact that there is no placebo controlled trial of any treatmen of endometriosis and therefore no information about the cours of the disease. Possibly asymptomatic endometriosis resolves spontaneously in most women. These uncertainties have resulted $\mathbf{m}$ some clinicians treating and others not treating asymptomatic endometriosis. The introduction of gestrinone (Roussel-UCLAF Paris) for phase III clinical trials provided a unique opportunity to perform a placebo controlled trial of a treatment of endometriosis and thus define the course of the disease and assess objectively the impact of treatment.

\section{Patients and methods}

All the patients were infertile and had been comprehensively investigate with no diagnosis being reached before laparoscopy. Their median age wăs 28 years (range 21-35) and median duration of infertility 36 months (range 18-72). Each patient was made fully aware of the purpose of the study and of the possibility of allocation to a placebo before giving written consent. $T \mathrm{~T}$ protocol was approved by the local ethical committee.

Study design-The study was a randomised, double blind placebo controlled trial of gestrinone in the treatment of asymptomatic endo metriosis. Forty patients were recruited after a laparoscopy at which mild of moderate asymptomatic endometriosis had been diagnosed. The disease wh staged using the American Fertility Society scoring system. ${ }^{10}$ In this system score of 1 to 5 signifies mild endometriosis, 6 to 15 moderate endometriosi and greater than 15 severe disease. Only those patients with asymptomatic 
disease which did not mechanically impede fertility were included. Patients were allocated at random to either placebo or gestrinone $2.5 \mathrm{mg}$ twice weekly. The treatment lasted 24 weeks, during which the patient was reviewed monthly. In the final week of treatment a repeat laparoscopy was performed. During this procedure the operator (EJT) was unaware of the previous laparoscopic findings and the patient's menstrual history and the observations were verified independently by another gynaecologist.

Statistical methods-We used the technique described by Pocock to determine the number of patients required for the study. ${ }^{11}$ Uncontrolled evidence suggested an expected improvement rate of at least $80 \%$ in the gestrinone group. ${ }^{12}$ The expected improvement rate in the placebo group was unknown, but we considered that the difference from treatment should be at least $50 \%$ for gestrinone to have a clinically relevant beneficial effect and therefore set the expected rate at $30 \%$. Type I and type II errors were set at 0.05 and 0.1 , respectively. By using these values 16 patients were required in each arm of the trial. In order to allow withdrawals 20 patients were recruited to each arm. Treatment scores before and after treatment were compared using a Wilcoxon rank sum analysis, as the scoring system is non-arithmetic. To simplify the clinical picture outcomes were compared for elimination of, improvement in, and deterioration of the disease. Elimination was defined as no visible disease and improvement as a lower and deterioration as a higher score at the second laparoscopy. The percentages of these observations were compared and the null hypothesis tested by $\chi^{2}$ analysis.

Gestrinone is a 19-nortestosterone derivative that has androgenic activity and is an antiprogesterone and antioestrogen..$^{1314}$ By interacting with hypothalamic and pituitary steroid receptors it decreases the secretion of luteinising hormone and follicle stimulating hormone. ${ }^{15}$ In some patients this inhibits follicular growth and ovulation, and initially the drug was tested as a contraceptive. ${ }^{16}$ It may be that the consequent withdrawal of oestrogen stimulation induces regression of endometriosis, or gestrinone may have this effect directly owing to its antioestrogenic, antiprogestational, and androgenic effects. ${ }^{12} \mathrm{~A}$ dose of either 5.0 or $2.5 \mathrm{mg}$ by mouth twice a week for six months successfully suppresses menstruation, and in three uncontrolled studies it was an effective treatment of endometriosis..$^{12118}$ The main side effects reported were weight gain, acne, seborrhoea, and hirsutism.

\section{Results}

Medians and ranges for age, Quetelet's index (weight $(\mathrm{kg}) / \mathrm{height}$ squared $\left(\mathrm{m}^{2}\right)$ ), and duration of infertility were similar for both groups. There were five withdrawals. One patient was found to be myxoedematous, one became pregnant within three months of entering the trial, one fractured her right tibia and fibula, and one withdrew during the first month of treatment because she decided against the possibility of being prescribed a placebo. The last patient withdrew after three months of treatment because she became depressed, which she claimed was unrelated to the medication. This left 18 patients who could be evaluated in the gestrinone group and 17 in the placebo group.

\section{EFFECTS OF GESTRINONE}

Gestrinone was well tolerated and no patient withdrew because of side effects. Eight women became amenorrhoeic, in five there were fewer than six episodes of vaginal bleeding, and in five there were six or more episodes. None of the bleeding was cyclical and in all patients it was less than the normal menstrual loss. At four weeks the mean weight increase in the gestrinone group was $2 \cdot 2 \mathrm{~kg}$ (95\% confidence limits $1 \cdot 19$ and $3 \cdot 27)$. A similar pattern was maintained throughout the treatment period. No significant weight change was observed in the placebo group. The increase in the gestrinone group was still present eight weeks after treatment.

There was no increase in the incidence of general side effects in the two groups. Table I compares the numbers of patients with seborrhoea or acne on examination in the two groups and shows that they were similar. The Ferriman and Gallwey score was used to assess hirsutism objectively. ${ }^{19}$ There was no significant difference in the distribution of scores either before $(z=-0.48 ; p=0.6)$ or at the end of treatment $(z=-1.05 ; p=0.3)$.

In comparison with placebo, gestrinone decreased mean plasma luteinising hormone and oestradiol concentrations. There was a small decrease in mean plasma total testosterone and a pronounced decrease in mean plasma sex hormone binding globulin concentrations. Roughly $99 \%$ of plasma total testosterone is bound to sex hormone binding globulin and the pronounced decrease in the concentration of this protein led to an approximate doubling of mean plasma free testosterone. There was no consistent abnormality in either the biochemical or haematological indices.

\section{SCORES BEFORE AND AFTER TREATMENT}

Table II compares the scores before and after treatment and details the change in scores in the placebo and gestrinone groups. A negative change in score represents improvement, while a positive change indicates deterioration. The pretreatment score was slightly higher in the placebo than gestrinone group $(z=1.99 ; p=0.047)$. The score is a combination of both endometriosis and adhesions, of which gestrinone will affect only the former. When the pretreatment scores were compared for visible disease only there was no difference $(z=1 \cdot 52 ; p=0 \cdot 13)$.

TABLE 1-Comparison of numbers of patients with either acne or seborrhoea in gestrinone and placebo treatment groups

\begin{tabular}{|c|c|c|c|c|}
\hline & & \multicolumn{3}{|c|}{ Weeks of treatment } \\
\hline & & 0 & 12 & 24 \\
\hline Acne & $\left\{\begin{array}{l}\text { Placebo } \\
\text { Gestrinone }\end{array}\right.$ & $\begin{array}{l}4 \\
2\end{array}$ & $\begin{array}{l}1 \\
2\end{array}$ & $\begin{array}{l}\mathbf{0} \\
\mathbf{0}\end{array}$ \\
\hline Seborrhoea & $\left\{\begin{array}{l}\text { Placebo } \\
\text { Gestrinone }\end{array}\right.$ & $\begin{array}{l}3 \\
1\end{array}$ & $\begin{array}{l}1 \\
1\end{array}$ & $\begin{array}{l}\mathbf{0} \\
\mathbf{0}\end{array}$ \\
\hline
\end{tabular}

TABLE II-American Fertility Society scores in placebo and gestrinone treatment groups before and after treatment

\begin{tabular}{|c|c|c|c|}
\hline Case No & Before treatment & After treatment & Change in score \\
\hline \multicolumn{4}{|c|}{ Placebo group } \\
\hline 1 & 1 & 0 & -1 \\
\hline 2 & 1 & 1 & 0 \\
\hline 3 & 1 & 2 & +1 \\
\hline 4 & 2 & 0 & -2 \\
\hline 5 & 2 & 0 & -2 \\
\hline 6 & 2 & 2 & 0 \\
\hline 7 & 2 & 3 & +1 \\
\hline 8 & 3 & 3 & 0 \\
\hline 9 & 3 & 5 & +2 \\
\hline 10 & 3 & 5 & +2 \\
\hline 11 & 3 & 5 & +2 \\
\hline 12 & 3 & 9 & +6 \\
\hline 13 & 5 & 1 & -4 \\
\hline 14 & 5 & 5 & 0 \\
\hline 15 & 6 & 4 & -2 \\
\hline 16 & 6 & 10 & +4 \\
\hline 17 & 6 & 12 & +6 \\
\hline \multicolumn{4}{|c|}{ Gestrinone group } \\
\hline 18 & 1 & 0 & -1 \\
\hline 19 & $i$ & 0 & -1 \\
\hline 20 & 1 & 0 & -1 \\
\hline 21 & 1 & 0 & -1 \\
\hline 22 & 1 & 0 & -1 \\
\hline 23 & 1 & 1 & 0 \\
\hline 24 & 1 & 1 & 0 \\
\hline 25 & 2 & 0 & -2 \\
\hline 26 & 2 & 0 & -2 \\
\hline 27 & 2 & 0 & -2 \\
\hline 28 & 2 & 0 & -2 \\
\hline 29 & 2 & 1 & -1 \\
\hline 30 & 2 & 2 & 0 \\
\hline 31 & 3 & 1 & -2 \\
\hline 32 & 3 & 2 & -1 \\
\hline 33 & 3 & 2 & -1 \\
\hline 34 & 4 & 1 & -3 \\
\hline 35 & 5 & 1 & -4 \\
\hline
\end{tabular}

The score for visible endometriosis after treatment was significantly less in the gestrinone group $(z=3.11 ; p=0.002)$. In order to counterbalance the difference in total scores between the two groups the change in score was compared by Wilcoxon's rank sum analysis. There was a significant difference in favour of the gestrinone group $(z=-2.74 ; p=0.006)$.

Table III compares the outcome in terms of the percentage of elimination, improvement, and deterioration of endometriosis in the two groups. Using $\chi^{2}$ analysis with Yates's correction for continuity we found a highly significant difference in improvement of the disease in the gestrinone group $\left(\chi^{2}=8.3 ; 1 \mathrm{df} ; \mathrm{p}=0.004\right)$ compared with the placebo group. There was a noticeable difference in elimination of the disease but this did not reach commonly accepted levels of statistical significance $\left(\chi^{2}=3.64 ; 1 \mathrm{df}\right.$; $p=0.057)$. The frequency of deterioration of the disease in the placebo group 
was significantly higher than that in the gestrinone group $(p=0.002$, two sided Fisher's exact test).

The placebo group was divided into those patients in whom the disease deteriorated $(n=8)$ and those in whom it did not $(n=9)$ and the medians and ranges for age, parity, Quetelet's index, and duration of infertility compared. There was no significant difference in the range of any of these factors between the two subgroups. Table II shows that there was no obvious predilection for lower scores to improve and higher scores to deteriorate. Hence it is not possible to predict from the initial score what the outcome will be if the disease is untreated.

TABLE III-Numbers of patients showing elimination, improvement, and deterioration of endometriosis in placebo and gestrinone treatment groups. (Figures in parentheses are $95 \%$ confidence intervals of percentages)

\begin{tabular}{lcc}
\hline & Placebo $(n=17)$ & Gestrinone $(n=18)$ \\
\hline Disease eliminated & $4(4$ to 43$)$ & $11(39$ to 84$)$ \\
Disease improved & $5(9$ to 50$)$ & $15(66$ to 100$)$ \\
Disease deteriorated & $8(23$ to 71$)$ & 0 \\
\hline
\end{tabular}

\section{Discussion}

This is the first randomised placebo controlled trial of any treatment of endometriosis. Observation of the course of asymptomatic mild and moderate disease over six months has shown that it deteriorates in a large number of patients $(95 \%$ confidence limits $23 \%$ and $71 \%$ ), which does not occur in those having treatment. We think that this level of deterioration in untreated disease means that finding endometriosis at laparoscopy, even if asymptomatic, warrants starting treatment. Gestrinone is an effective treatment of endometriosis.

The recommendation to treat asymptomatic disease is further supported by our finding that in three patients in the placebo group the degree of deterioration included the appearance of adhesions that resulted in ovarian enclosure. These adhesions may mechanically impede future fertility and their appearance is of considerable importance in infertile women, who are commonly diagnosed with asymptomatic disease. The finding that no factor, including the original score, could accurately predict improvement or deterioration in the placebo group also supports the recommendation that asymptomatic disease should always be treated.

The study has shown a beneficial impact of gestrinone on the course of asymptomatic endometriosis. The laparoscopy was performed in the final week of treatment, which raises two criticisms of the study. Firstly, there may have been quiescent areas of endometriosis which would have become visible if stimulated by oestradiol. There is conflicting evidence about the relation between endometriosis and ovarian steroids and recent studies have reported that the disease can be neither morphologically ${ }^{2021}$ nor functionally ${ }^{22}$ considered simply as ectopic endometrium. It is therefore doubtful whether the size or symptomatology of the disease would have been altered by a short period of ovarian steroid stimulation. The second criticism is that the study does not show a permanent effect of the drug. The trial did not address this question, but as the drug is unlikely to alter whatever predisposes a person to endometriosis possibly the disease will recur. In order to answer the question it would be necessary to. perform a further laparoscopy some months after completing treatment.

The drug was well tolerated and the absence of androgenic side effects contradicts previous uncontrolled studies. ${ }^{1218}$ The presence of the placebo control balanced any apparent increase in any side effect in the gestrinone group. The number of patients means that the study cannot rule out a small increase in the incidence of androgenic side effects but it discounts a severe effect. As the gain in weight with gestrinone did not disappear after treatment probably it represents an increase in muscle and adipose tissue and not simply fluid retention. This is probably a result of the androgenicity of the drug and is the most tangible side effect.

In summary this study has shown a beneficial impact of treatment on the course of asymptomatic endometriosis. The usual course for the disease to deteriorate in a proportion of women, and as this unpredictable we recommend that all patients should be treated. $\stackrel{\mathbb{Q}}{\stackrel{2}{\varrho}}$

EJT was supported by a grant from Roussel Laboratories Ltd.

\section{References}

1 Hirst JC. Conservative treatment and therapeutic test for endometriosis by androgens. Am

Obstet Gynecol 1947;53:483-7.
2 Kistner RW. The effects of new synthetic progestogens on endometriosis in the human fema Fertil Steril 1965;16:61-79.

3 Dmowski WP, Kapetanakis E, Scommegna A. Variable effects of danazol on endometriosis at fo dose levels. Obstet Gynecol 1982;59:408-15.

4 Low RA, Roberts ADG, Lees DAR. A comparative study of various dosages of danazol in the treatment of endometriosis. Br O Obstet Gynaecol 1984;91:167-71.

5 Buttram VC, Reiter RC, Ward S. Treatment of endometriosis with danazol: report of a 6 yegी prospective study. Fertil Steril 1985;43:353-60.

6 Riedel HH, Semm K. Extragenital endometriosis and sterility-clinical experience with a 3-st僃 therapy. Prog Clin Biol Res 1982;112:187-94.

7 Shaw RW, Fraser HM, Boyle H. Intranasal treatment with luteinising hormone-releasin hormone agonist in women with endometriosis. Br Med f 1983;287:1667-9.

8 Shriock E, Monroe SE, Henzl M, Jaffe RB. Treatment of endometriosis with a potent agonist gonadotropin-releasing hormone (nafarelin). Fertil Steril 1985;44:583-8.

9 Hull MGR, Glazener CMA, Kelly NJ, et al. Population study of causes, treatment, and outcome infertility. Br Med J 1985;291:1693-7.

10 American Fertility Society. Classification of endometriosis. Fertil Steril 1979;32:633-4.

11 Pocock SJ. Statistical methods for determining trial size in clinical trials. In: Clinical trials. है practical approach. Chichester: John Wiley and Sons, 1983:123-33.

12 coutinho EM. Treatment of endometriosis with gestrinone (R-2323), a synthetic antiestroget antiprogesterone. Am 7 Obstet Gynecol 1982;144:895-8.

13 Azadian-Boulanger G, Secchi J, Laraque F, et al. Action of a mid-cycle contraceptive (R2323) the human endometrium. Am $\mathcal{f}$ Obstet Gynecol 1976;125:1049-56. 14 Kaupilla A, Isomaa $V$, Ronnbert $L$, et al. Effect of gestrinone in endometriosis tissue and
endometrium. Fertil Steril 1985;44:466-70.

15 Proulx L, Labrie F, Veilleux R, Azadian-Boulanger G. Actions of progestin and androgens at the hypothalamo-adenohypophyseal level in the female rat. In: Raynaud J-P, Ojasoo T, Martini E, eds. Medical management of endometriosis. New York: Raven Press, 1984:149-62.

16 Sakiz E, Azadian-Boulanger G, Laraque F, Raynaud JP. A new approach to estrogen-free contraception based on progesterone receptor blockade by mid-cycle administration of ethey norgestrienone (R2323). Contraception 1974;10:467-74.

17 Coutinho EM, Housson JM, Azadian-Boulanger G. Treatment of endometriosis with gestrino -five years' experience. In: Raynaud J-P, Ojasoo I, Martini L, eds. Medical management if

18 Mettler L, Semm K. Three-step therapy of genital endometriosis in cases of human infertility with lynestrenol, danazol or gestrinone administration in the second step. In: Raynaud J-P, Ojas 6 Tynestrenol, danazol or gestrinone administration in the second step. In: Raynaud J-P, Ojas 69 19 Ferriman GD, Gallwey JD. Clinical assessment of body hair growth in women. $f$ Clin Endocrivet Metab GD, Gallwey JD.

20 Schweppe K-W, Wynn RM. Ultrastructural changes in endometriotic implants during th menstrual cycle. Obstet Gynecol 1981;58:465-73.

21 Vasquez G, Cornillie F, Brosens IA. Peritoneal endometriosis: screening electron microscopy aref histology of minimal pelvic endometriotic lesions. Fertil Steril 1984;42:696-703.

22 Haney AF, Hamdwerger S, Weinbert JB. Peritoneal fluid prolactin in infertile women wi endometriosiș: lack of evidence of secretory activity by endometrial implants. Fertil Stent? 1984;42:935-8.

(Accepted 28 November 1986)

\section{YEARS AGO}

A good deal of dissatisfaction has been expressed in many quarters at the substitution of the word "margarine" for that of "butterine" in the Bill now before Parliament. Sir Lyon Playfair, in a letter to the Times, in which he advocates the use of the word "butter-substitute," points out that "'maf garine' is scientific nonsense and a practical absurdity. Stearine and margarine are solid fats used to give solidity to candles, and do not resemb soft butter in any degree. If the scientific name had been desired, it shour have been 'oleo-margarine,' which is a soft fat resembling butter;" and ho asks: "Why should the working-classes be perplexed with a scientific name Butterine," he adds, "is a wholesome butter-substitute made from the fat of the ox, as butter is made from the fat of the cow. It contains about 95 per cent. of the same fatty materials as those in ordinary butter, and differs only by not containing the aromatic fatty acids which give to good butter its delicious flavour. But if the poor choose to buy ox-butter at $6 \mathrm{~d}$. per $1 \mathrm{~b}$., why should they have difficulties in procuring it in favour of cow-butter at 1s. pest lb." For the efficient working of a measure of this kind it is a matter of the first importance that there should be a correct use of terms, and such as afe readily understood by the class of persons who are affected by its provision Butterine, however, is, it may be argued, itself misleading, as implying variety of food made from milk; this butterine is certainly not. If margarine or oleo-margarine be objected to, then some new specific or fang designation might be devised; but we can well understand the existit objections to the name of "butter" to one which it is contended is more less sailing under false pretences. (British Medical fournal 1887;ii:97.) 